\title{
Chronic Demyelinating Inflammatory Polyradiculoneuropathy Associated With Sarcoidosis
}

Mansour M, Souissi W, Beyrouti $\mathbf{R}^{*}$, Abouhassen A and Mrissa R

Department of Neurology, Military Hospital of Tunis, Tunisia

*Corresponding author: Rahma Beyrouti, Department of Neurology, Military Hospital of Tunis, Tunisia, Tel: 21628267032; E-mail: rahma.beyrouti@gmail.com

Received date: January 5, 2017; Accepted date: January 28, 2017; Published date: February 1, 2017

Copyright: ( 2017 Mansour M, et al. This is an open-access article distributed under the terms of the Creative Commons Attribution License, which permits unrestricted use, distribution, and reproduction in any medium, provided the original author and source are credited.

\begin{abstract}
Sarcoidosis is an inflammatory multisystem disorder, usually involving the lung, the skin, the lymph nodes, and the eyes. The prevalence of clinical involvement of the nervous system is estimated to be about $5 \%$ to $15 \%$ [1]. Both central and peripheral nervous system can be affected. Sarcoid polyneuropathy is a rare and clinically heterogeneous disorder that may be the initial presentation of sarcoidosis [2]. Only a few cases have been reported of chronic demyelinating inflammatory polyradiculoneuropathy (CIDP) associated with sarcoidosis. We report a clinical course of a patient presented with a sensorimotor demyelinating polyneuropathy with secondary axonal loss few years after being diagnosed with lung sarcoidosis.
\end{abstract}

Keywords: Sarcoidosis; Polyneuropathy; CIDP; Nerve biopsy

\section{Case Report}

A 60-year-old woman, with medical history of lung sarcoidosis diagnosed in 2003 treated by $40 \mathrm{mg}$ prednisolone daily, was admitted in our neurological department in March 2011 for paresthesia and burning sensation in her two hands evolving for five months.

Neurological examination revealed mild distal limb weakness, generalized hyporeflexia, impairment of touch, pain, and temperature sensations in both hands. Vibration sense was severely affected in the higher limbs, especially in the left side. Patient was ataxic with a positive Romberg's sign.

Electrophysiological study demonstrated bilateral elongated distal latencies, reduced nerve conduction velocities, and conduction blocks respectively in the median, the ulnar and the peroneal nerves (Table 1). It also objectified delayed $\mathrm{F}$ response in the median, the ulnar and the tibial nerves (Table 2) fulfilling the EFNS/PNS diagnostic criteria for CIDP.

Cerebrospinal fluid (CSF) analysis revealed an elevated protein level $(0.54 \mathrm{~g} / \mathrm{L}$; normal range $0.16-0.4 \mathrm{~g} / \mathrm{L})$ without pleocytosis. Magnetic resonance imaging (MRI) of the brain and the spinal cord was normal. Nerve biopsy was not performed because of patient's refusal. Serologies of Lyme, hepatitis B and C and human immunodeficiency virus were negatives. Levels of thyroid hormones, glycaemia and Vitamin B12 were within normal limits. Screening tests for autoantibodies, including antinuclear antibody (Ab), anti-SS A/SS B Ab, anticardiolipin $\mathrm{Ab}$, antineutrophil cytoplasmic Abs (P-ANCA and CANCA) and tumor markers were also unrevealing.

The patient received initially IV methylprednisolone for 3 days ( $1 \mathrm{gr} /$ day), then oral prednisolone of $60 \mathrm{mg} /$ day for 2 months followed by a very gradual reduction. Thereafter, the patient was maintained on oral prednisolone ( $40 \mathrm{mg}$ daily) in association with azathioprine $(100 \mathrm{mg}$ daily). Slight improvement in the muscle strength was observed.

\begin{tabular}{|c|c|c|c|c|c|c|}
\hline Nerve/Sites & Lat. (ms) & Amplitude (mV) & Amp.1-2 (\%) & Intensity Stim. & Dist. (cm) & Vit. $(\mathrm{m} / \mathrm{s})$ \\
\hline \multicolumn{7}{|l|}{ R Median } \\
\hline Wrist & 6.00 & 1.4 & 100 & $60 \mathrm{~mA}$ & - & - \\
\hline Elbow & 18.60 & 0.6 & 42.85 & $100 \mathrm{~mA}$ & 27 & 21.4 \\
\hline Erb & - & - & - & - & - & - \\
\hline \multicolumn{7}{|l|}{ L Median } \\
\hline Wrist & 8.85 & 0.9 & 100 & $50 \mathrm{~mA}$ & - & - \\
\hline Elbow & 43.30 & 0.1 & 11 & $50 \mathrm{~mA}$ & - & - \\
\hline 3. Erb & & - & - & - & - & - \\
\hline \multicolumn{7}{|l|}{ R Ulnar } \\
\hline Wrist & 4.45 & 2.4 & 100 & $59 \mathrm{~mA}$ & - & - \\
\hline
\end{tabular}




\begin{tabular}{|c|c|c|c|c|c|c|}
\hline Elbow & 14.9 & 0.7 & 26.16 & $59 \mathrm{~mA}$ & 4 & - \\
\hline Axilla & 10.05 & 0.6 & 85.71 & $100 \mathrm{~mA}$ & 29 & 27,8 \\
\hline \multicolumn{7}{|l|}{ L Ulnar } \\
\hline Wrist & 3.30 & 1.2 & 100 & $84 \mathrm{~mA}$ & - & - \\
\hline Elbow & 14.35 & 0.7 & 58.33 & $84 \mathrm{~mA}$ & 24 & 21.7 \\
\hline Axilla & 19.60 & 0.4 & 57.14 & $100 \mathrm{~mA}$ & 12 & 22.9 \\
\hline \multicolumn{7}{|l|}{ L Tibial } \\
\hline Internal malleole & 9.90 & 0.4 & 100 & $51 \mathrm{~mA}$ & - & - \\
\hline \multicolumn{7}{|l|}{ R Tibial } \\
\hline Internal malleole & 8.25 & 0.9 & 100 & $61 \mathrm{~mA}$ & - & - \\
\hline \multicolumn{7}{|l|}{ L Peroneal } \\
\hline Ankle & 5.35 & 2.2 & 100 & $51 \mathrm{~mA}$ & - & - \\
\hline Collar & 13.15 & 1.8 & 81.81 & $73 \mathrm{~mA}$ & 33 & 42.3 \\
\hline \multicolumn{7}{|l|}{ R Peroneal } \\
\hline Ankle & 5.50 & 0.5 & 100 & $55 \mathrm{~mA}$ & - & - \\
\hline Collar & 12.05 & 0.5 & 100 & $55 \mathrm{~mA}$ & 30 & 45.8 \\
\hline
\end{tabular}

Table 1: Motor conduction velocities.

\begin{tabular}{|l|l|l|}
\hline Nerf & Lat $\mathbf{F}(\mathbf{M s})$ & F-M $(\mathbf{m s})$ \\
\hline L Tibial & BLOC & - \\
\hline R Tibial & 50.90 & 52.43 \\
\hline L Median & 23.65 & 24.64 \\
\hline R Median & BLOC & - \\
\hline L Ulnar & 27.30 & 27.80 \\
\hline R Ulnar & BLOC & - \\
\hline
\end{tabular}

Table 2: F wave.

\section{Discussion}

Peripheral nervous system involvement in sarcoidosis is rare, affecting $2 \%$ of patients [3]. Its patterns are varied and include multiple mononeuropathies, focal or multifocal neuropathy, and CIDP as in our case [1].

Typically, systemic symptoms of sarcoidosis precede the neuropathy. In some cases, nervous system involvement can be the presenting form of sarcoidosis. Ducray et al. [4] reported a case of a 36-year-old-man who first presented two relapses of chronic inflammatory demyelinating polyneuropathy (CIDP) before the diagnosis of sarcoidosis was made. In 2015, Singhal et al. [5], reported also the clinical, electrophysiological, and pathological findings of a patient who carried a diagnosis of sensory-predominant CIDP for over a decade but was ultimately found to have sarcoidosis. In cases of suspected peripheral nerve sarcoidosis, biopsy of both nerve and

muscle tissue may increase the diagnostic yield and help rule out other rare inflammatory, infectious, or neoplastic causes of neuropathies.

Several explanations for the pathogenesis of neuropathy associated with sarcoidois have been suggested: such as endoneural granuloma, perivascular granuloma and necrotizing epineural vasculitis [5].

Evidence-based guidance for treatment of neurosarcoidosis is limited by its rarity. Glucocorticoids are considered the first-line treatment. In refractory cases a second immune modulator is often added. Our patient did not well respond to steroid but showed considerable improvement with azathiopirine. Fewer than $10 \%$ of patients do not respond to any immune modulatory therapy.

\section{Conclusion}

Sarcoid polyneuropathy is not only rare, but it also presents with a variety of clinical syndromes which often delay the diagnosis of this challenging disorder. This diagnosis should be considered in every patient with CIDP even in the absence of systemic signs. In cases of suspected peripheral nerve sarcoidosis, nerve biopsy may help diagnose this treatable disorder.

\section{References}

1. Pawate S, Moses H, Sriram S (2009) Presentations and outcomes of neurosarcoidosis: A study of 54 cases. QJM: An International Journal of Medicine 102: 449-460.

2. Saifee TA, Reilly MM, Ako E, Rugg-Gunn F, Brandner S, et al. (2011) Sarcoidosis presenting as acute inflammatory demyelinating polyradiculoneuropathy. Muscle Nerve 43: 296-298. 
Citation: Mansour M, Souissi W, Beyrouti R, Abouhassen A, Mrissa R (2017) Chronic Demyelinating Inflammatory Polyradiculoneuropathy Associated With Sarcoidosis. J Neurol Disord 5: 328. doi:10.4172/2329-6895.1000328

Page 3 of 3

3. Scott TF, Yandora K, Valeri A, Chieffe C, Schramke C (2007) Aggressive therapy for neurosarcoidosis: Long-term follow-up of 48 treated patients. Archives of Neurology 64: 691-696.

4. Ducray F, Costedoat-Chalumeau N, Bouhour F, Rousset H, Vial C (2007) [Chronic inflammatory demyelinating polyneuropathy and sarcoidosis: fortuitous association?]. Rev Neurol (Paris) 163: 3S85-3S89.
5. Singhal NS, Irodenko VS, Margeta M, Layzer RB (2015) Sarcoid polyneuropathy masquerading as chronic inflammatory demyelinating polyneuropathy. Muscle Nerve 52: 664-668. 